\title{
ACAT: o trabalhador como protagonista da análise de acidentes de trabalho
}

\section{Claudia Osorio}

Departamento de Psicologia da Universidade Federal Fluminense

\begin{abstract}
O dispositivo de análise coletiva de acidentes de trabalho (ACAT) tem como objetivo analisar acidentes de modo a propiciar, por uma via de análise participativa, o aumento da vitalidade dos ofícios. Foi utilizado durante dois anos em um hospital público, buscando-se aperfeiçoá-lo e observar os efeitos que propiciava. Referenciado na teoria da clínica da atividade, o método consiste em levar o trabalhador a recriar a situação do acidente, deslocando-se para a posição de observador de seu trabalho. $O$ trabalhador é convidado a mostrar como deu-se o acidente e o analista do trabalho apresenta-lhe questões sobre suas escolhas quanto aos caminhos possíveis, interrupções sofridas e outras. A dupla acidentado-analista registra em um diagrama a sucessão de eventos, privilegiando a experiência do acidentado. São então promovidas discussões grupais de diversos acidentes. Os resultados demonstram que o dispositivo produz efetivamente o deslocamento do trabalhador para a posição de co-analista de seu trabalho, rompendo cristalizações que impedem o desenvolvimento dos ofícios constitutivos do trabalho em saúde.
\end{abstract}

Palavras-chave: Atividade, Subjetividade, Processo de trabalho, Acidente de trabalho.

Collective Analysis of Work Accidents: the worker as protagonist of the analysis of occupational accidents

The Collective Analysis of Work Accidents device aims at analysing accidents and to propitiate the increase of the professions' vitality. We used it during two years in a public hospital, searching to perfect it and observe the effects it rendered. The method is based on the theory of the clinic of activity. It consists in conducting the worker to recreate the situation of the accident, transporting himself to the position of observer of his/her work. The worker is invited to show how the accident came about and the work analyst presents him questions about his choices as to the possible ways, interruptions occurred and others. The pair accidented worker-analyst registers in a diagram the succession of events, privileging the accidented person's experience. Group discussions on several accidents are then held. The results show that the device effectively transports the worker to the position of coanalyst of their work, shattering crystallizations that hinder the development of the professions which compose the health team.

Keywords: Activity, Subjectivity, Work process, Work accident.

\section{Introdução}

E ste artigo apresenta um método de intervenção em saúde do trabalhador que vem sendo desenvolvido, desde 2002, em um hospital público da cidade do Rio de Janeiro, Brasil. A partir de 1996, a Comissão de Saúde do Trabalhador do hospital desenvolveu um programa de controle e prevenção de acidentes com exposição a instrumentos pérfuro-cortantes e fluidos corporais ${ }^{1}$. Esse programa foi iniciado em uma visão pedagógica de transferência de conhecimentos e informações e foi sendo modificado com uma inclusão crescente do saber da experiência e de propostas de construção coletiva de conhecimentos sobre o processo de trabalho e de soluções para os problemas identificados. Colocou-se então como objetivo construir um método de análise dos acidentes de trabalho, que fizesse fluir o saber da

1 Trata-se do Hospital dos Servidores do Estado, situado no bairro da Saúde, na cidade do Rio de Janeiro. O hospital dispõe em sua estrutura de um serviço de saúde do trabalhador que à época, de 1996 a 2006, desenvolvia, sobretudo, ações de promoção e prevenção em saúde do trabalhador voltadas para seus funcionários e trabalhadores terceirizados. Nossa ação junto a esse serviço deu-se pela colaboração entre o hospital e o Curso de Psicologia da Universidade Federal Fluminense com fins de estágio e pesquisa. 
experiência na invenção de novos modos de fazer. Esse método tem sido denominado ACAT: Análise Coletiva de Acidentes de Trabalho.

O método descrito neste artigo visa interferir positivamente na re-criação de conteúdos cognitivos, renovando os recursos objetivos e subjetivos de que o trabalhador dispõe para recriar a cada dia sua prática. Assim, recria-se também a prática tradicional do analista do trabalho: o especialista sai do lugar daquele que aconselha para o daquele que compartilha a produção de caminhos e soluções.

Dizendo de outra maneira, a ampliação do poder de ação do trabalhador, tomada como principal objetivo do método, exige a produção de novas subjetividades, a produção de sujeitos capazes de produzir formas de enfrentar novas e velhas situações, confrontando-se com sua experiência e com a experiência coletiva. Nessa perspectiva, o principal observador da atividade de trabalho deve ser o próprio trabalhador e não um especialista em análise do trabalho. O especialista deve oferecer-se como um apoio ao deslocamento do trabalhador para o lugar de observador de sua própria atividade.

Com o desenvolvimento de seus ofícios, espera-se que os trabalhadores produzam ou incorporem a seus modos de fazer regras relativas a sua saúde e segurança. ${ }^{2}$

Nos hospitais públicos do Brasil, não temos uma tradição de participação, mas sim de centralização de decisões; a representação sindical é frágil e não é substituída ou complementada por outras formas de organização política. Há ainda, uma descrença acentuada na possibilidade de que os coletivos de trabalho possam influenciar a organização de suas próprias atividades, observando-se um quadro predominantemente defensivo frente a organização do trabalho. Buscando recursos para ultrapassar as dificuldades impostas por essa realidade, tomamos como ponto de partida a análise e a prevenção dos acidentes de trabalho com pérfuro-cortantes e exposição a fluidos biológicos. O programa de controle e prevenção de acidentes do hospital em questão surgiu como proposta em 1996, num seminário de saúde do trabalhador. Iniciado numa visão pedagógica de transferência de conhecimentos e informações, o programa foi sendo modificado com a inclusão cada vez maior do saber da experiência e de propostas de construção coletiva de soluções para os problemas identificados.

\section{Trabalho, subjetividade e saúde mental}

A saúde do trabalhador no Brasil situa-se no domínio da saúde coletiva, recebendo contribuições de diferentes disciplinas, num caminho dito, por diversos autores, interdisciplinar e multiprofissional (Machado, 1997; Minayo-Gomez \& Thedim-Costa, 1997; Seligmann-Silva, 1994). Pode-se também pensar a saúde do trabalhador como transdisciplinar, rompendo os limites das disciplinas e reconstruindo-se cotidianamente com suas múltiplas referências teóricas. A saúde do trabalhador não se define por limites disciplinares, mas por metas e eixos de ação, dentre os quais temos a luta pela saúde, produzida nas transformações dos processos, na eliminação dos riscos e na superação das condições precárias de trabalho. Um outro eixo está na valorização das demandas e dos conhecimentos advindos da experiência, considerando-se a participação dos trabalhadores como fecunda e indispensável.

Esse campo tem recebido aportes diversos no que diz respeito ao conhecimento das relações entre trabalho e subjetividade. Cabe questionar quanto e como essas concepções 
respondem aos objetivos acima apresentados, de ampliação da capacidade normativa dos trabalhadores, ampliando sua autonomia com relação à gestão de seu próprio trabalho.

No Brasil é bastante conhecida a concepção, de origem francesa, da psicodinâmica do trabalho, que encontra na luta contra o sofrimento psíquico no trabalho seu ponto de partida. A partir de 1980, as pesquisas de Christophe Dejours e seu grupo deslocaram-se da patologia para a normalidade, colocando a seguinte questão: como faz a maioria dos sujeitos que trabalham para fazer frente aos constrangimentos encontrados nas situações de trabalho sem sofrer graves descompensações? Mais tarde, em 1992, a mudança de denominação de sua corrente de pesquisas, de psicopatologia para psicodinâmica do trabalho, virá reforçar essa orientação (Dejours, 1999, p. 198). Para a psicodinâmica do trabalho, o sofrimento é o ponto de partida e a origem da mobilização da inteligência e da subjetividade. Encontrando resistências no real à realização de si mesmo, o sujeito deve encontrar saídas para a angústia, soluções de compromisso que se externalizam em atitudes defensivas. Para fazer frente ao real que os limita, os trabalhadores produzem estratégias coletivas ou individuais de defesa e, assim, escapam à descompensação emocional e à doença mental. $\mathrm{O}$ estudo dos sistemas defensivos, pelos quais os sujeitos buscam conjurar o real que resiste, é o principal recurso teórico da psicodinâmica do trabalho (Clot \& Litim, 2001).

Interessantes que sejam, essas contribuições estão referidas a uma concepção de homem e de subjetividade que valoriza a noção de indivíduo, indivíduo esse regido pela racionalidade, em busca de sua própria identidade e movido por uma angústia original da qual não pode se desembaraçar (Dejours, 1999). Para a psicodinâmica do trabalho, a subjetividade é entendida "como produção psíquica da luta contra o sofrimento", enquanto para a clínica da atividade, ela é entendida "como produto da atividade" (Dejours, 1999, p. 206).

Uma outra contribuição aos estudos da subjetividade pode ser identificada nos estudos do estresse provocado nas relações de trabalho. Os pesquisadores do estresse buscam estabelecer os laços de causa e efeito entre variáveis psicossociais e respostas fisiológicas, suscitando, a partir de uma concepção de homem como mecanismo biológico, intervenções voltadas para a regulação desse mecanismo (Chanlat, 1990), elegendo o sofrimento psíquico - aqui definido em função de sintomas relacionados ao estresse continuado - como categoria central de seus estudos. Tais estudos tendem a ter como conseqüência a indicação de saídas individualizadas para a gestão do estresse.

Existem também propostas que, partindo do conceito de estresse, assumem causalidade sociológica, como o modelo demanda-controle-apoio social proposto por Karasek (1979). Essa linha teórica informa um grupo crescente de estudos de caráter epidemiológico no Brasil (Alves et al., 2004; Araújo et al., 2003a; Araújo et al., 2003b; Nascimento Sobrinho et al., 2006; Porto et al., 2006). Tais pesquisas podem ser um importante instrumento de gestão da saúde do trabalhador, trazendo esclarecimentos acerca do perfil de morbimortalidade relacionado a determinado processo de trabalho, mas não fornecem dispositivos de intervenção com o objetivo de ampliação do poder de ação dos trabalhadores.

As ferramentas conceituais produzidas nesses enfoques, embora venham sendo importantes na construção do campo de discussão da relação entre subjetividade e trabalho, não fornecem recursos suficientes para intervenções que tenham como objetivo central propiciar a ampliação do poder de ação dos trabalhadores, dando potência aos movimentos de produção de relações solidárias e de invenção de novos possíveis.

Em uma outra linha, na qual os conceitos da psicologia social têm um lugar central, temos a contribuição de Leny Sato. Na década de 90 essa autora tomou a discussão sobre risco em uma forma crítica e qualitativa, destacando a noção de penosidade (Sato, 1991). Por essa noção, os esforços exigidos pela organização do trabalho são avaliados, havendo uma contraposição ao reducionismo de pensar o risco como algo exclusivamente observável e 
mensurável em sua ocorrência e em suas conseqüências. Temos aí um avanço na inclusão do subjetivo como material de investigação científica. Mais adiante, a autora adota uma abordagem etnográfica (Sato, 2002) a fim de analisar processos de trabalho (Sato, 2001, 2007).

Numa outra vertente, inspirada nos trabalhos de Ivar Oddone e da ergonomia francofônica, observamos o desenvolvimento de pesquisas sobre trabalho e subjetividade que tomam a atividade como categoria central de estudo e o trabalho como atividade dialógica; aí situam-se os estudos da clínica da atividade (Clot, 2006). As ferramentas conceituais produzidas por essa visada abrem novas possibilidades de intervenção para a psicologia do trabalho. Na clínica da atividade, a compreensão da relação entre trabalho e subjetividade não é centrada na luta contra o sofrimento, mas na atividade de trabalho como fonte permanente de recriação de novas formas de viver. O motor da transformação e do desenvolvimento dos ofícios, das atividades que nele se dão e dos trabalhadores, está na provocação que se dá na atividade, em suas dimensões inter e transpessoal, nas polêmicas que aí se travam.

A clínica da atividade retoma o caminho, apontado por Oddone, de atenção às possibilidades de superação de impasses pelos próprios trabalhadores; por essa via dá-se um deslocamento do psicólogo da posição de protagonista da investigação e da produção de inovações, ficando a condução do processo em mãos operárias. De acordo com Clot (2001, p. 8), Oddone teve o mérito e a originalidade de avaliar, em seu trabalho junto aos operários da Fiat, o impasse produzido pela ação centrada na denúncia de condições de trabalho inaceitáveis. Oddone voltou-se para a pesquisa dos recursos dos próprios trabalhadores, recursos muitas vezes insuspeitados, de que eles podem lançar mão para a promoção e proteção de sua própria saúde (Oddone, Re \& Briante, 1981). Para Oddone (Clot, 2001),

trata-se de fazer uma outra psicologia do trabalho consagrando todos os esforços à busca de um só objetivo: aumentar o poder de ação dos coletivos de trabalhadores sobre o ambiente de trabalho real e sobre si mesmos. A tarefa consiste, então, em inventar ou reinventar os instrumentos dessa ação, não mais protestando contra os constrangimentos, mas pela via de sua superação concreta (p. 9). ${ }^{3}$

Como dissemos acima, para a clínica da atividade a subjetividade é entendida como produto da atividade (Clot, 2006). A atividade é sempre mais do que os gestos realizados, passíveis de observação direta. Sujeita a pressões, normas, situações mutantes, "a atividade sempre se realizar em um plano de interferências de intenções, exigindo decisões do operador que deve, então, proteger as suas de outras intenções concorrentes" (Maia, 2006, p. 28). Sendo a atividade uma ação estabelecida entre outras concorrentes, Clot (2001) a definirá de uma forma ampliada. Para além de uma concepção amorfa da atividade de trabalho, propõe incluir nesse conceito os conflitos do real. A atividade não é somente aquilo que se faz. $\mathrm{O}$ real da atividade é também o que não se faz, aquilo que não se pode fazer, o que se tenta fazer sem conseguir (os fracassos), aquilo que se desejaria ou poderia-se fazer, aquilo que não se faz mais, aquilo que se pensa ou sonha-se poder fazer em outro momento. É necessário acrescentar aqui um paradoxo freqüente: atividade é aquilo que se faz para não fazer o que tem que ser feito ou ainda o que se faz sem desejar fazer, sem contar o que deve ser refeito. A atividade possui então um volume que transborda a atividade realizada. Em matéria de atividade, o realizado não possui o monopólio do real. A fadiga, o desgaste psíquico são compreendidos tanto por aquilo que os trabalhadores não podem fazer, quanto por aquilo que fazem.

Sendo assim, diz-nos Miguel Maia (2006):

3 O dispositivo que conhecemos no Brasil como Mapa de Riscos, incluído nas Normas Regulamentadoras do Trabalho graças a uma luta empreendida pelos trabalhadores organizados, foi originalmente desenvolvido na Itália, por Oddone e seus parceiros. 
compreendemos que a atividade exige a mobilização da subjetividade e, portanto, a análise do trabalho, para ser efetiva, precisará dispor de metodologias que levem em consideração a produção de subjetividade, o que dito de outra forma, faz com que a análise do trabalho tenha que incluir em seus estudos o que se produz naquele que produz enquanto produzindo (p. 28).

No trabalho dá-se a construção coletiva de recursos para a ação, constituindo-se o gênero da atividade de trabalho, um conceito que, nessa perspectiva, não se refere à diferença entre os sexos dos trabalhadores, mas remete a um plano coletivo de constituição do trabalho. Para a clínica da atividade, o trabalhar é sempre uma dimensão coletiva, mesmo que se desenvolva por um único trabalhador. Na formulação de Maia (2006),

Toda atividade de trabalho pode ser entendida como um encontro entre corpos, atravessamentos múltiplos que se agenciam, se interconectam, demandando escolhas e decisões e, portanto, tornando todo trabalho uma atividade de criação. Mais do que um mero executor de tarefas, o trabalhador constitui e é constituído pela sua atividade, sendo ao mesmo tempo produtor e produto, estando presente a capacidade de afetar e de ser afetado. Um trânsito no qual o coletivo devém singular e o singular devém trabalhador e, simultaneamente, o singular devém coletivo e o coletivo devém gênero da atividade, de forma que a competência se produz em uma emergência no e através do plano no qual singular e coletivo não são dicotômicos, mas causas/efeitos heterogenéticos de atravessamentos de corpos (pp. 30-31).

Esse referencial comum, do qual o gênero é constituído e constituinte, não deve ser entendido como o somatório dos referenciais individuais, como se ele fosse o todo do qual os indivíduos seriam as partes, pois ele possui um componente impessoal, ou genérico, no sentido de que sendo de todos a ninguém pertence. $O$ gênero constitui-se na dimensão transpessoal do ofício, acima mencionada. Ele, na realidade, é uma espécie de "corpo intermediário" (Clot, 2006) que permite, por exemplo, que dois trabalhadores que não se conhecem possam ser capazes de se coordenarem eficazmente para realizar um objetivo difícil dentro de um contexto complexo de trabalho, por possuírem um gênero de atividade semelhante, que lhes facilita a maneira de "pegar as coisas e lidar com as pessoas" (Clot, 2001) dentro de um contexto profissional. Esse referencial elaborado em comum estabelece as regras não escritas e não imutáveis em uma situação comunicacional que supõe a elaboração comum". Ele inscreve o saber-fazer considerado na história de um coletivo, o coletivo de ofício.

Singular e coletivo ao mesmo tempo, o gênero é sempre plural, de forma que podemos entender que em toda atividade que se processa concorrem gêneros diferenciados, exigentes de um tempo diferente do prescrito para que possa haver a elaboração comum, só possível se privilegiarmos a formação de coletivos de trabalho. $O$ tempo de produção sem considerar o tempo necessário a essa elaboração comum, tão característico da organização do trabalho contemporâneo, em realidade impede de trabalhar, já que, na acepção da clínica da atividade, ter acesso ao gênero e dispor do tempo necessário para dele apropriar-se e expandilo é fundamental para o processamento da atividade, sem essa formalização, combinando regras escritas e não escritas, dificulta-se que o gênero exerça sua função de meio de ação, fazendo com que "aqueles que trabalham estejam entregues a si mesmos em uma situação que se degrada" (Clot, 1999a, p. 30), amputados em sua capacidade de agir, em sofrimento psíquico.

À clínica da atividade interessará, então, compreender as relações entre o real e o realizado e em que condições a experiência vivida pode ser ou vir a ser um meio de viver outras experiências, já que, estudando detalhadamente aquilo que os trabalhadores fazem, aquilo que eles dizem do que fazem, mas também aquilo que eles fazem do que eles dizem, nós 
desembocamos em um reconhecimento das possibilidades insuspeitadas pelos próprios trabalhadores (Clot, 2001).

Propõe-se, na perspectiva da clínica da atividade, que se inclua o trabalhador como pesquisador ativo de sua atividade, fazendo da análise do trabalho tanto um meio de desenvolvimento dos conhecimentos científicos e práticos, quanto um meio de desenvolvimento dos ofícios e de formação dos trabalhadores.

\section{A ACAT}

Buscando construir um método de análise de acidentes situado nessa perspectiva, da clínica da atividade, propôs-se a Análise Coletiva de Acidentes de Trabalho (ACAT). Nesse método, a tarefa consiste em elucidar, para o outro e para si mesmo, as questões pertinentes ao curso de acontecimentos que culminaram em um acidente. Essa elucidação é fruto de deslocamentos que se dão numa relação dialógica. Nesse diálogo, o trabalhador acidentado, como portador da experiência, dirige-se a si mesmo, a seus colegas e ao analista. Por sua vez, o analista, como portador de conhecimentos formalizados, dirige-se em sua análise a si mesmo, a seus pares e aos trabalhadores implicados.

$\mathrm{Na}$ construção da análise do acidente, busca-se conhecer as múltiplas situações encadeadas que resultaram no evento em foco, deslocando o trabalhador acidentado e seu grupo para a posição de observadores de seu próprio trabalho. A experiência de trabalho construída até então servirá de instrumento para viver uma nova experiência, a de analisar sua própria atividade, experiência que possibilita a renovação dos recursos objetivos e subjetivos que sustentam os modos de operar; o gênero profissional em questão pode ser renovado, ampliando-se a capacidade de ação dos trabalhadores, inclusive no que diz respeito à prevenção dos acidentes.

A primeira etapa da ACAT é uma encenação do acidente. $O$ analista do trabalho solicita ao trabalhador acidentado que mostre como ocorreu o acidente. O trabalhador é solicitado a levar o analista ao local de trabalho em que o acidente ocorreu, propiciando que a dupla analista do trabalho e trabalhador acidentado possa vivenciar, em diferentes perspectivas, a situação de trabalho em que o acidente se deu e poderia se repetir. Os materiais usados devem ser retomados, na medida do possível, os gestos devem ser refeitos em uma simulação da situação que anteriormente culminou no acidente. A partir da solicitação do analista, e com o correr da encenação, o trabalhador é levado a observar como ele próprio realizou ou realiza habitualmente a atividade em questão.

O fato de que o analista não seja alguém do mesmo ofício propicia um estranhamento daquilo que, somente entre pares, poderia ser tomado como óbvio, prescindindo de explicitação. Falar a quem participa do mesmo gênero profissional produz um outro discurso, diferenciado do falar a um pesquisador ou a um profissional de saúde do trabalhador, que desconhecem, por definição, os detalhes da atividade específica do acidentado.

Para que esse deslocamento do trabalhador possa ser um instrumento de desenvolvimento para ele próprio, é preciso que haja uma relação de confiança e de solidariedade entre ele e o analista do trabalho. A tarefa de analisar o acidente não pode ser obrigatória, ela tem necessariamente que ser uma demanda do próprio trabalhador. ${ }^{4}$

\footnotetext{
4 Essa relação, no caso em questão, foi construída em parte pela legitimidade já alcançada pela Comissão de Saúde do Trabalhador (CST) do hospital. Ao se acidentar, o trabalhador do hospital, tenha ele a função de médico, enfermeiro, técnico de enfermagem ou qualquer outra, é orientado a ir a uma consulta com um infectologista e a notificar o acidente à CST. Todas as demais etapas são de participação voluntária: o trabalhador de saúde é convidado a colaborar com a prevenção de acidentes e deve sempre saber que pode não aceitar.
} 
A segunda etapa é a construção de um desenho esquemático das diversas linhas e cruzamentos que culminaram no acidente. Esse diagrama deverá ser construído coletivamente, em uma colaboração entre o analista do trabalho e o trabalhador acidentado. Descrever a ação para o analista, desenhar e ver desenhado o entrecruzamento de eventos que constroem uma atividade que poderia parecer simples, produz um efeito de distanciamento de si mesmo: permite ao trabalhador conhecer seu trabalho ao mesmo tempo em que conhece e recria seu modo singular de agir.

Um novo encontro põe em discussão as elaborações pessoais que foram suscitadas na e a partir da primeira etapa. Nesse segundo encontro podem ser discutidas algumas providências imediatas a serem tomadas pelo trabalhador ou a serem propostas a sua equipe ou a outras instâncias.

No movimento provocado por essas etapas sucessivas dá-se a elaboração que possibilita novas estilizações da atividade profissional (Clot, 2006).

Os resultados das análises feitas caso a caso são postos em discussão em duplas ou em grupos convocados especialmente para esse fim. Os trabalhadores que passaram pela experiência de acidentar-se e, em seguida, observar e discutir seu acidente, em um processo de autoconfrontação com sua atividade, são chamados a debater essa experiência com seus pares. São postos em debate os acidentes sofridos pelos trabalhadores presentes, a partir dos diagramas elaborados na primeira etapa. As questões suscitadas nessa etapa não serão as mesmas que surgiram na situação anterior, em que o diálogo faz-se entre o trabalhador, seu objeto e o analista do trabalho. Há agora um novo interlocutor, o colega que conhece e participa da mesma atividade profissional.

Nesse processo de análise, os horizontes da atividade deslocam-se com os sujeitos, na multiplicidade dos gêneros que se cruzam: o gênero da atividade comum, o gênero da análise de acidentes e o gênero científico que é trazido pelos pesquisadores. Ao ser atravessada por outros gêneros, a atividade descola-se do gênero no qual ela realiza-se habitualmente, tornando-o visível (Clot, 2000, p. 31). No método proposto há uma análise coletiva da atividade. $\mathrm{O}$ pesquisador e os colegas de trabalho não têm as mesmas questões, as mesmas certezas, as mesmas dúvidas; são diferentes do protagonista e são também diferentes entre si. Tais diferenças são introduzidas, seja de forma explícita, seja pelos silêncios, pelos momentos de impaciência ou pela voz mais animada a partir de um determinado ponto. Procurando atingir o outro, explicar-lhe seu ponto de vista, o seu trabalho cotidiano, o trabalhador acaba por descobrir algo novo em si mesmo, sem necessariamente ter procurado.

Nesse processo, a análise feita e refeita desenvolve a atividade, produzindo novas possibilidades para o dia-a-dia de trabalho; novos caminhos que poderão, do diálogo interpessoal entre acidentados, passar a fazer parte do patrimônio do gênero, da dimensão transpessoal da atividade.

\section{A experiência de desenvolvimento do método}

No período de agosto de 2003 a abril de 2005, foram analisados 79 acidentes e foram realizadas duas oficinas de discussão em grupo desses acidentes e do procedimento de análise adotado, a ACAT. ${ }^{5}$

5 A pesquisa Análise coletiva dos acidentes de trabalho no hospital: aperfeiçoamento de uma metodologia para o desenvolvimento da saúde do profissional de saúde foi uma atividade vinculada ao estágio supervisionado e à extensão universitária realizados na Comissão de Saúde do Trabalhador do Hospital dos Servidores do Estado por alunos do curso de Psicologia da Universidade Federal Fluminense. Contou com três bolsistas de iniciação científica (duas bolsas do CNPq e uma da FAPERJ). Recebeu também apoio da FAPERJ na forma de Auxílio de Pesquisa. A pesquisa foi aprovada pelo Comitê de Ética em Pesquisa. 
Foram observadas mudanças na descrição do processo de trabalho entre uma e outra etapa da análise, desde a primeira encenação do acidente até a discussão grupal, caracterizando o desenvolvimento ou a ampliação da relação do trabalhador com seu trabalho.

Um exemplo pode ser dado de modo sucinto.

Uma auxiliar de enfermagem dirigiu-se ao leito do paciente para fazer uma coleta de sangue para exame e feriu-se com a agulha utilizada. Relatou que, enquanto finalizava o procedimento, o acompanhante do paciente moveu-se, esbarrou na profissional e provocou o acidente. $\mathrm{O}$ espaço existente no box é exíguo, o que favorece esse tipo de acidente. $\mathrm{Na}$ fase seguinte da análise, a profissional refletia: "na próxima vez, vou alertar o acompanhante a sentar-se para não atrapalhar". No relato inicial, a movimentação do acompanhante e o espaço existente não são vistos como parte a ser considerada pelo profissional de enfermagem no seu trabalho; a noção de objeto, o planejamento da atividade, ou suas preocupações, estão centradas no manejo dos instrumentos e no braço do paciente. $\mathrm{O}$ espaço e o acompanhante existem como dados externos, que não teriam porque serem incluídos como objeto da ação do profissional de enfermagem. No segundo diálogo entabulado entre analista do trabalho e o profissional acidentado, este passa a levantar as possibilidades de manejo daquelas relações, denotando uma ampliação do seu objeto de trabalho. O objeto de trabalho, que era inicialmente a veia do paciente, seu braço ou seu corpo, passa a ser o paciente e seu acompanhante: alguém das relações pessoais do paciente, possivelmente mobilizado afetivamente pela situação, que pode movimentar-se de modos não esperados pela profissional.

Observe-se que a realidade atual do hospital público faz com que o paciente seja, freqüentemente, um paciente-que-tem-acompanhante ${ }^{6}$. A presença do acompanhante representa uma mudança importante no processo de trabalho, exigindo um desenvolvimento do ofício - do gênero profissional - que dê suporte a essa modificação nas exigências da atividade. $\mathrm{O}$ acompanhante não considerado torna-se um estorvo; se bem incluído pode ser um recurso.

Estando incluído o acompanhante no plano de trabalho, espera-se que esse tipo de acidente tenda a ser menos freqüente. Se o acompanhante é figura presente, com freqüência cada vez maior, o desenho dos boxes, suas dimensões e mobiliário, deve contemplar essa realidade. O preparo dos procedimentos técnicos (colher sangue, por exemplo) deve incluir a definição do lugar do acompanhante: deve-se pedir que ele se retire? Solicitar que permaneça em um local definido? Explicar-lhe o que vai ser feito? Deu-se uma ampliação do objeto de trabalho, podendo haver o desenvolvimento de recursos objetivos e subjetivos para lidar com esse novo objeto.

Levada à discussão em grupos, essa situação pôde gerar a ampliação do horizonte de atenção dos profissionais envolvidos, as dimensões consideradas nas reformulações espaciais e de organização do trabalho.

\section{Conclusão}

O objetivo da perspectiva aqui adotada é intervir de modo a provocar o desenvolvimento dos ofícios. O que importa não é propriamente produzir conhecimento sobre os ofícios, seu objetivo não é recuperar o vivido da atividade, mas provocar o saber de

6 Estatutos específicos tornaram obrigatória a aceitação no hospital de acompanhantes para crianças e para idosos. Além disso, no hospital considerado, são admitidos acompanhantes para outros pacientes considerados graves. 
ofício para provocar seu desenvolvimento. As intervenções propostas buscam mais do que conhecer, analisar ou denunciar as formas de dominação e sofrimento existentes, buscam uma aliança, com as possibilidades que os trabalhadores têm de criar e recriar suas próprias relações com o mundo.

$\mathrm{Na}$ atividade realizada está sempre presente um conflito. Para que um caminho seja tomado, um gesto seja feito, outros modos de fazer foram deixados de lado, outras intenções foram menos fortes. A inclusão das preocupações na análise das ocupações dá oportunidade ao trabalhador e ao analista do trabalho de acessar os processos de subjetivação que são parte integrante da atividade.

Nessa linha desenvolve-se o conhecimento que advém da experiência, ampliando aquilo que nele é dizível. Produz-se conhecimento sobre a atividade e seus revezes, ao mesmo tempo em que se criam recursos para ultrapassá-los. Nessa perspectiva importa que o protagonista da análise seja o trabalhador, como portador do saber tácito e como aquele que mais diretamente pode transformá-lo.

\section{Referências}

Alves, M. G. M., Chor, D., Faerstein, E., Lopes, C. S. \& Werneck, G. L. (2004). Versão resumida da "Job Stress Scale": adaptação para o português. Revista de Saúde Pública, 38 (2), 164-171.

Araújo, T. M. (2007). Saúde mental e trabalho. Texto apresentado ao I Simpósio Brasileiro de Saúde do Trabalhador. Abrasco, Conservatória. [Digitado]

Araújo, T. M. (1999). Trabalho e distúrbios psíquicos em mulheres trabalhadoras de enfermagem. Tese de Doutorado, Instituto de Saúde Coletiva, Universidade Federal da Bahia, Salvador.

Araújo, T. M., Aquino E., Menezes, G., Santos, C. O. \& Aguiar, L. (2003). Aspectos psicossociais do trabalho e distúrbios psíquicos entre trabalhadoras de enfermagem. Revista de Saúde Pública, 37 (4), 424-433.

Araújo, T. M., Reis, E. J. F. B., Kavalkievcz, C., Delcor, N. S., Paranhos, I., Silvany-Neto, A. M., Carvalho, F. M., Porto, L. A. \& Wernick, R. (2003). Saúde e trabalho: dando visibilidade aos processos de desgaste e adoecimento docente a partir de uma rede de produção coletiva. Educação em Revista, 37, 183-212.

Clot, Y. (2006). A função psicológica do trabalho. Petrópolis: Vozes.

Clot, Y. (2001). Éditorial. Éducation permanente: clinique de l'activité et pouvoir d'agir, 146, 7-16.

Clot, Y. (2000). Genres et styles en analyse du travail. Concepts et méthodes. Travailler: Revue Internationale de Psychopathologie et de Psychodynamique du Travail, 4, 7-42.

Dejours, C. (1999). Psychologie clinique du travail et tradition compréhensive. In Y. Clot (Org.), Les histoires de la psychologie du travail: approche pluridisciplinaire (pp. 195-219). Toulouse: Octarès.

Karasek, R. (1979). Job demand, job decision latitude, and mental strain: implications for job redesign. Administrative Science Quarterly, 24, 285-308.

Machado, J. H. M. (1997). Processo de vigilância em saúde do trabalhador. Cadernos de Saúde Pública, 13 (supl. 2), 33-45.

Maia, M. A. B. (2006). O corpo invisivel do trabalho: cartografia dos processos de trabalho em saúde. Dissertação de Mestrado, Instituto de Ciências Humanas e Filosofia, Universidade Federal Fluminense, Niterói.

Minayo-Gomez, C. \& Thedim-Costa, S. M. da F. (1997). A construção do campo da saúde do trabalhador: percurso e dilemas. Cadernos de Saúde Pública, 13 (supl. 2), 21-32. 
Nascimento Sobrinho, C. L, Carvalho, F. M., Bonfim, T. A. S. et al. (2006). Condições de trabalho e saúde mental dos médicos de Salvador, Bahia, Brasil. Cadernos de Saúde Pública, 22 (1), 131-140.

Oddone, I., Re, A. \& Briante, G. (1981). Redécouvrir l'expérience ouvrière: vers une autre psychologie du travail? Paris: Messidor.

Osorio, C., Machado, J. \& Minayo-Gomez, C. (2005). Proposição de um método de análise de análise coletiva dos acidentes de trabalho no hospital. Cadernos de Saúde Pública, 21 (2), 517-524.

Osorio da Silva, C. (2002).Vida de hospital: a produção de uma metodologia para o desenvolvimento da saúde do profissional de saúde. Tese de Doutorado, Escola Nacional de Saúde Pública, Fiocruz, Rio de Janeiro.

Osorio da Silva, C. \& Oliveira, N. (1999). Intervenções em saúde do trabalhador: psicólogos numa comissão de saúde do trabalhador num hospital geral público no Rio de Janeiro. Revista do Departamento de Psicologia - UFF, 11 (1), 40-50.

Porto, L. A., Carvalho, F. M., Oliveira, N. F. et al. (2006). Associação entre distúrbios psíquicos e aspectos psicossociais do trabalho de professores. Revista de Saúde Pública, 40 (5), 818-826.

Sato, L. (2007). Processos cotidianos de organização do trabalho na feira livre. Psicologia $\mathcal{E}$ Sociedade, 19 (especial 1), 95-102.

Sato, L. (2002). Prevenção de agravos a saúde do trabalhador: replanejando o trabalho através das negociações cotidianas. Cadernos de Saúde Pública, 18 (5), 1147-1166.

Sato, L. (2001). Contribuindo para desvelar a complexidade cotidiana através da investigação etnográfica em Psicologia. Psicologia USP, 12 (2), 29-47.

\section{Endereço para correspondência:}

claudiaosorio@terra.com.br 